\title{
In vivo effect of two first-line ART regimens on inflammatory mediators in male HIV patients
}

\author{
Vasiliki D Papakonstantinou ${ }^{1 *}$, Maria Chini ${ }^{2}$, Nikos Mangafas ${ }^{2}$, George M Stamatakis ${ }^{1}$, Nickolaos Tsogas ${ }^{2}$, \\ Alexandros B Tsoupras ${ }^{1}$, Katherina Psarra ${ }^{3}$, Elizabeth Fragopoulou ${ }^{4}$, Smaragdi Antonopoulou, \\ Panagiotis Gargalianos ${ }^{5}$, Constantinos A Demopoulos ${ }^{1}$ and Marios-C Lazanas ${ }^{2}$
}

\begin{abstract}
Background: Persistent immune activation and inflammation are lying behind HIV-infection even in the setting of ART mediated viral suppression. The purpose of this study is to define the in vivo effect of two first-line ART regimens on certain inflammatory mediators in male HIV patients.

Methods: Male, naive, HIV-infected volunteers were assigned either to tenofovir-DF/emtricitabine/efavirenz (Group_T) or abacavir/lamivudine/efavirenz (Group_A). Platelet Activating Factor (PAF) levels and metabolic enzymes together with HIV-implicated cytokines (IL-1 beta, IL-6, IL-8, IL-10, IL-12p70, TNFa) and VEGF were determined for a 12-month period. Differences within each group were determined by non-parametric Friedman and Wilcoxon test, while the differences between the groups were checked by ANOVA repeated measures.

Results: Both ART regimens present pronounced effect on inflammatory mediators, resulting in decreased PAF levels and Lipoprotein-associated phospholipase A2 (LP-PLA2) activity for tenofovir-containing regimen and same as baseline PAF levels with a peak though at the $3^{\text {rd }}$ month as well as elevated Lp-PLA2 activity for abacavir-containing regimen.

Conclusions: Studies regarding the effect of first-line ART regimens on inflammation may be beneficial in preventing chronic morbidities during HIV-treatment. From this point of view, the present study suggests an anti-inflammatory effect of tenofovir-containing ART, while the temporary increase of PAF levels in abacavir-containing ART may be the link between the reported cardiovascular risk and abacavir administration.
\end{abstract}

Keywords: Platelet activating factor, Cytokines, Inflammation, Human immunodeficiency virus, Cardiovascular disease, Tenofovir-DF, Abacavir, Efavirenz

\section{Background}

The progress of ART over the years has turned HIVinfection from lethal into a chronic disease. However, immune activation and inflammation are lying behind effectively treated patients causing various non-AIDS morbidities as cardiovascular or renal diseases and cancers [1]. Consequently chronic HIV-associated inflammation is now considered a significant factor for the above-mentioned conditions while elevated inflammatory and coagulation markers can predict higher morbidity and even mortality in HIV infected population [2-4].

\footnotetext{
* Correspondence: papakonstantinou.v@gmail.com

${ }^{1}$ Faculty of Chemistry, National \& Kapodistrian University of Athens,

Panepistimioupolis Zografou, 15771 Athens, Greece

Full list of author information is available at the end of the article
}

During HIV-infection specific cells of the immune system become targets of the virus and secrete in response several inflammatory factors as cytokines and chemokines [5]. The effect of antiretrovirals on cytokines' levels seems contradictory. Abacavir is thought to be associated with increased cardiovascular risk as it up-regulates pro-inflammatory cytokines and CRP [6,7]. Nevertheless, its use was not always associated with increased levels of inflammatory markers [8], showing a similar effect with tenofovir-DF [9]. In addition both antiretrovirals had no effect on coronary endothelial cell gene transcription and protein expression of cytokines, supporting that the increased cardiovascular risk is probably not through the direct endothelial activation pathways [10]. The inconsistent effect of ART on cytokines' levels maybe indicates another inflammatory mediator to be responsible 
for the increased cardiovascular risk associated with abacavir use.

Platelet Activating Factor (PAF) is one of the most potent inflammatory factors and a significant signaling molecule of the immune system, considered as a primitive and universal cellular mediator $[11,12]$ that participates in both physiological and pathological processes $[13,14]$. Concerning PAF biosynthesis, there are two distinctive pathways named de novo, responsible for the constant PAF biosynthesis, and remodeling, activated as a direct response to acute inflammatory processes [15], with key-enzymes being dithiothreitol-insensitive PAFcholinephosphotransferase (PAF-CPT, EC 2.7.8.16) and lyso-PAF:acetyl-CoA acetyltransferase (lyso-PAF-AT, EC 2.3.1.67) [16,17], respectively. PAF catabolism is moderated by PAF-specific acetylhydrolase (PAF-AH, EC 3.1.1.47), and its plasma isoform, Lipoprotein-associated phospholipase A2 (Lp-PLA2) [18].

PAF is thought to be implicated in the progression of HIV-infection as studies have revealed that HIV-infected monocytes overexpress PAF through Tat protein $[19,20]$. It was found that altered host cells and their subproducts as Tat protein induce PAF biosynthesis via cytokines, as Tumor Necrosis Factor-alpha (TNF $\alpha$ ), and growth factors, as Vascular Endothelial Growth Factor (VEGF) [21,22]. The produced PAF, as a secondary mediator, participates in several processes like monocyte cell recruitment and increased vascular permeability, which can lead to various morbidities [2,23,24]. A great variety of antiretrovirals, backbone and HAART regimens exhibit in vitro inhibitory effect against PAF activity [25] while many studies have underlined the need for combined antiretroviral and anti-PAF action in drugs like piperazine and its developed derivatives [26-28]. Patients with early or asymptomatic HIV-infection before ART initiation have shown increased activity of PAF biosynthetic enzymes and Lp-PLA2 indicating a persistent inflammatory condition [29]. It has also been proposed that Lp-PLA2 could play the role of a sensitive marker as its increased levels in HIV and AIDS patients may be a physiological response protecting the host against PAF or other oxidized phospholipids [30]. The implication of PAF in HIV-infection is further supported by the beneficial effect of PAF antagonists administration in animal models for HIV-1 encephalitis $[31,32]$ as well by the improvement of neuropsychological test scores in HIVpatients under lexipafant, the first PAF antagonist used in HIV-associated cognitive impairment [33].

The scope of this paper is to determine for the first time the in vivo effect of two first line ART regimens on PAF levels in HIV naive patients along with several already established inflammatory biomarkers implicated in HIV-infection. The hypothesis states that tenofovirDF/emtricitabine/efavirenz would down regulate PAF levels in contrast to abacavir/lamivudine/efavirenz based on preliminary data concerning the effect of the above regimens on PAF enzymes [34,35].

\section{Methods \\ Study design}

Study enrollment begun after obtaining approval from the scientific board of the Red Cross General Hospital of Athens in Greece and all volunteer patients have signed the informed consent according to the Declaration of Helsinki. The volunteers $(n=18)$ were recruited from the $3^{\text {rd }}$ Internal Medicine Department-Infectious Diseases Unit, Red Cross General Hospital, Athens, Greece. All participants were male, treatment naïve, and asymptomatic HIV-infected patients as determined by the presence of antibodies against HIV measured by enzyme-linked immunosorbent assay (ELISA) and confirmed by Western blot. All patients were at CDC A2 clinical stage and fulfilled the criteria for ART initiation according to the European [36] and International guidelines [37]. The patients were assigned in 2 groups at the discretion of the clinicians. Group_T $(n=8$, mean age $=46 \pm 10$ years, $50 \%$ smokers) received coformulated tenofovir-DF/emtricitabine with efavirenz and Group_A $(\mathrm{n}=10$, mean age $=35 \pm 11$ years, $70 \%$ smokers) received co-formulated abacavir/lamivudine along with efavirenz. The exclusion criteria include inflammatory diseases (periodontal or autoimmune disease, other diseases (diabetes, hypertension), allergies or any additional medication that may affect PAF levels. The study lasted for 12 months and the blood samples were collected before (baseline, defined as 0 months) and after 1, 3, 6, 9 and 12 months of treatment initiation.

\section{Determination of PAF levels}

The isolation and purification of PAF was according to the method of Demopoulos et al. [38]. Briefly, $10 \mathrm{~mL}$ of blood were collected from each human subject and poured immediately into $40 \mathrm{~mL}$ of absolute ethanol. The mixture was stirred and centrifuged at $300 \times \mathrm{g}$ for $10 \mathrm{~min}$ at room temperature. The supernatant and the pellet were extracted separately according to the Bligh and Dyer method [39] and the chloroform phase in each case was stored at $-20^{\circ} \mathrm{C}$. The supernatant chloroform extract contains PAF molecules that are loosely bounded to plasma proteins and lipoproteins, named as free PAF, while the pellet extract contains PAF molecules strongly bounded to cellular structures, named as bound PAF. The above extracts were purified on silicic acid column chromatography that was eluted with $45 \mathrm{~mL}$ of methanol/water $(1: 1.5, \mathrm{v} / \mathrm{v})$, followed by $50 \mathrm{~mL}$ of methanol/ water $(2: 1, \mathrm{v} / \mathrm{v})$. The initial $45 \mathrm{~mL}$ (containing the bulk of proteinaceous and other non-lipid impurities) were 
discarded while the PAF containing eluents were further purified by HPLC (Hewlett-Packard series 1100) on a cation-exchange column. The solvent system consisted of an isocratic elution of acetonitrile/methanol/water (61:31:8, v/v/v) slightly modified from the one described in the original paper [38]. The eluted substances were detected using UV detection at $208 \mathrm{~nm}$. The examined samples were dissolved in BSA $1.25 \%$ in saline and its PAF levels were measured by the aggregatory activity (by a 400 VS aggregometer Chrono-Log, USA) towards washed rabbit platelets. PAF levels are expressed as $\mathrm{fmol} / \mathrm{mL}$ of blood.

\section{Isolation of plasma, platelets and leukocytes}

The isolations of plasma, platelets (HPs) and leukocytes (HLs) were carried out as previously described [40]. Briefly, human blood was collected from an antecubital vein and distributed into a polyethylene tube containing anticoagulant in a ratio of blood/anticoagulant: 9/1, in a total volume of $10 \mathrm{~mL}$. Each sample underwent multiple centrifugations in order to isolate plasma, platelets and leukocytes.

\section{Enzymatic assays}

Dithiothreitol-insensitive PAF-CPT and lyso-PAF-AT activity assays were performed on the homogenates of leukocytes and platelets. PAF-AH activity assays were performed on the homogenates of leukocytes and platelets as well as Lp-PLA2 activity assays on plasma as previously described [40]. The enzyme activity is expressed as $\mathrm{pmol} / \mathrm{min} / \mathrm{mg}$ of total protein or $\mathrm{pmol} / \mathrm{min} / \mu \mathrm{L}$ of plasma.

\section{Biochemical markers and immunological analysis}

Clinical biochemical markers were measured by a Siemens Dimension RxL automatic analyzer. CD4 cell counts were defined using Tetra One System on the EPICS XL flow cytometer, while viral load was determined using the Versant HIV-1 RNA 3.0 assay. Plasma levels of IL$1 \beta$, IL-6, IL-8, IL-10, IL-12p70, TNF $\alpha$ and VEGF were determined on a BD FACS Canto II Flow cytometer using CBA flex set cytokine kit and data analysis was performed by FCAP Array DIVA software. Cytokines are expressed as $\mathrm{pg} / \mathrm{mL}$ of plasma.

\section{Statistical analysis}

Normal distribution was checked by P-P graphs using Shapiro-Wilk criterion. The results are expressed as median values and interquartile range $\left(25^{\text {th }}-75^{\text {th }}\right)$. Differences within each group during the overall 12-month treatment were determined by non-parametric Friedman (displayed as $\mathrm{p}_{\text {time }}$ ) analysis. Wilcoxon test was used to compare the difference of specific time point with the baseline values within each group (displayed as $\mathrm{p}_{\text {specific- }}$ time-point). After ranking the values, the differences between the groups were checked by repeated measures ANOVA and are displayed as $\mathrm{P}_{\text {intervention }}\left(\mathrm{P}_{\text {int }}\right)$ for the overall and $\mathrm{P}_{\text {specific-time-point }}$ for each time point in particular. Viral load changes are reported in a logarithmic scale for convenience and not in order to normalize the value. Statistical significance was considered as $\mathrm{p}<0.05$.

\section{Results}

\section{Anthropometric and biochemical characteristics}

Anthropometric and biochemical characteristics of patients are shown in Additional file 1, presenting no difference between the two groups $\left(P_{\text {int. }} \mathrm{S}>0.05\right)$.

In both groups, viral load is progressively reduced during the study period ( $\left.p_{\text {time_A/T }}<0.001\right)$, while CD4 cell counts are gradually increased $\left(\mathrm{p}_{\text {time_A } / \mathrm{T}}<0.001\right)$ even from the $1^{\text {st }}$ month of treatment. White blood cell count remains stable in both groups $\left(\mathrm{p}_{\text {time_}} \mathrm{T}=0.205, \mathrm{p}_{\text {time_A }}=\right.$ 0.091), belonging to the minimum level of the normal range.

Despite the variations in the lipid profile of each group, the values remain within the normal range. Particularly, in both groups total cholesterol $\left(\mathrm{p}_{\text {time_T }}=0.007, \mathrm{p}_{\text {time_A }}=\right.$ $0.001), \operatorname{LDL}\left(\mathrm{p}_{\text {time_T }}=0.028, \mathrm{p}_{\text {time_A }}=0.007\right)$ and HDL $\left(\mathrm{p}_{\text {time_T }}=0.008, \mathrm{p}_{\text {time_A }}=0.002\right)$ are increased while triglycerides remain stable $\left(\mathrm{p}_{\text {time_T }}=0.170\right)$ in Group_T and are increased in Group_A ( $\left.\mathrm{p}_{\text {time_A }}=0.001\right)$.

\section{Effect of ART regimens on PAF levels}

Bound PAF levels in Group_T are differentiated through the 12-month period $\left(\mathrm{p}_{\text {time } \mathrm{T}}=0.010\right.$ ) and especially they are decreased at the $1^{\text {st }}, 3^{\text {rd }}, 6^{\text {th }}$ and $12^{\text {th }}$ month $\left(\mathrm{p}_{1}=\right.$ $0.008, \mathrm{p}_{3}=0.016, \mathrm{p}_{6}=0.039$ and $\mathrm{p}_{12}=0.008$, respectively). Bound PAF levels in Group_A are also differentiated during the study period $\left(\mathrm{p}_{\text {time_A }}=0.028\right)$, with a single increase at the $3^{\text {rd }}$ month $\left(\mathrm{p}_{3}=0.016\right)$, (Table 1$)$. There is no overall differentiation between the groups $\left(P_{\text {int }}=0.357\right)$, however a differentiation is achieved at the $3^{\text {rd }}$ month $\left(\mathrm{p}_{3 \_\mathrm{A}-\mathrm{T}}=0.038\right)$ and a borderline one at the $12^{\text {th }}$ month $\left(\mathrm{p}_{12 \_\mathrm{A}-\mathrm{T}}=0.083\right)$; (Figure 1$)$.

Regarding Free PAF levels, in Group_T they are borderline differentiated through the study period $\left(\mathrm{p}_{\text {time_}} \mathrm{T}=\right.$ 0.068) while in Group_A they remain stable throughout the treatment period $\left(\mathrm{p}_{\text {time_A }}=0.719\right)$, with no differentiation at any time point for both groups nor between them $\left(\mathrm{P}_{\text {int }}=\right.$ 0.917), (Additional file 2).

\section{Effect of ART regimens on PAF basic biosynthetic enzymes (PAF-CPT, lyso-PAF-AT) in leukocytes and platelets}

As far as it concerns PAF biosynthesis in leukocytes, the specific activity of PAF-CPT in Group_T is differentiated during the 12 -month period $\left(\mathrm{p}_{\text {time_T }}=0.009\right)$ with gradually reductions from the $1^{\text {st }}$ to the $12^{\text {th }}$ 
Table 1 PAF levels and metabolic enzymes of ART groups

\begin{tabular}{|c|c|c|c|c|c|c|c|c|c|}
\hline Parameter & Groups & Baseline/0 month & $1^{\text {st }}$ month & $3^{\text {rd }}$ month & $6^{\text {th }}$ month & $9^{\text {th }}$ month & $12^{\text {th }}$ month & $p_{\text {time }}$ & Pint. \\
\hline \multirow{4}{*}{ Bound PAF (fmol/mL) } & \multirow{2}{*}{$\mathrm{T}$} & 1.66 & $1.11^{*}$ & $0.90^{*}$ & $1.08^{*}$ & 1.12 & $0.74^{*}$ & \multirow{2}{*}{0.010} & \multirow{2}{*}{0.357} \\
\hline & & $(1.35-2.02)$ & $(0.70-1.18)$ & $(0.70-1.30)$ & $(0.70-1.54)$ & $(0.70-2.11)$ & $(0.70-1.18)$ & & \\
\hline & \multirow{2}{*}{ A } & 0.90 & 1.10 & $5.54^{*}$ & 1.42 & 1.14 & 1.53 & \multirow{2}{*}{0.028} & $P_{3}=0.038$ \\
\hline & & $(0.70-6.20)$ & $(0.70-2.41)$ & $(0.97-17.29)$ & $(0.78-3.85)$ & $(0.93-1.71)$ & $(0.78-2.39)$ & & $P_{12}=0.083$ \\
\hline \multirow{4}{*}{ PAF-CPT in HLs (pmol/min/mg) } & \multirow{2}{*}{ T } & 546.50 & $336.00^{*}$ & $191.50^{*}$ & $232.00^{*}$ & $338.50^{*}$ & $288.50^{*}$ & \multirow{2}{*}{0.009} & \multirow{4}{*}{0.304} \\
\hline & & $(416.50-730.25)$ & $(182.50-451.75)$ & $(114.50-518.00)$ & $(147.25-461.25)$ & $(231.25-381.25)$ & $(236.50-341.75)$ & & \\
\hline & \multirow{2}{*}{ A } & 344.50 & 257.00 & 438.00 & 344.00 & 495.00 & $445.00^{*}$ & \multirow{2}{*}{0.085} & \\
\hline & & $(215.25-787.75)$ & $(221.75-515.25)$ & $(183.00-535.50)$ & $(173.50-795.50)$ & $(252.50-755.00)$ & (330.00-920.00) & & \\
\hline \multirow{4}{*}{ Lyso-PAF-AT in HLs (pmol/min/mg) } & \multirow{2}{*}{ T } & 22.95 & 12.40 & 12.20 & $8.40^{*}$ & $13.85^{*}$ & $16.40^{*}$ & \multirow{2}{*}{0.002} & \multirow{4}{*}{0.818} \\
\hline & & $(11.90-26.65)$ & $(10.75-33.27)$ & $(8.02-28.07)$ & $(2.22-12.92)$ & $(8.47-17.60)$ & $(9.77-19.75)$ & & \\
\hline & \multirow{2}{*}{ A } & 9.15 & 10.75 & $20.60^{*}$ & 10.55 & 13.50 & 12.50 & \multirow{2}{*}{0.141} & \\
\hline & & $(6.12-19.82)$ & $(5.25-22.20)$ & $(7.42-35.75)$ & $(6.85-27.27)$ & $(8.00-27.75)$ & $(6.50-24.25)$ & & \\
\hline \multirow{4}{*}{ PAF-AH in HLs $(\mathrm{pmol} / \mathrm{min} / \mathrm{mg})$} & \multirow{2}{*}{ T } & 69.17 & 55.68 & 70.71 & $54.18^{*}$ & $46.32^{*}$ & $45.81^{*}$ & \multirow{2}{*}{0.002} & \\
\hline & & $(42.94-106.97)$ & $(32.34-80.52)$ & $(37.47-114.14)$ & $(33.09-65.45)$ & $(28.23-62.67)$ & $(25.79-51.56)$ & & 070 \\
\hline & \multirow{2}{*}{ A } & 50.54 & 52.68 & $64.03^{*}$ & 61.30 & 57.05 & 52.24 & \multirow{2}{*}{0.180} & 0.132 \\
\hline & & $(46.57-58.78)$ & $(34.37-72.78)$ & $(50.80-92.62)$ & $(32.55-75.06)$ & $(36.49-66.05)$ & $(40.54-61.08)$ & & \\
\hline \multirow{4}{*}{ Lp-PLA2 (pmol/min/ $/ \mu \mathrm{L})$} & \multirow{2}{*}{ T } & 29.35 & 26.15 & 34.20 & 29.10 & $26.40^{*}$ & $27.15^{*}$ & \multirow{2}{*}{0.003} & \multirow{2}{*}{0.017} \\
\hline & & $(24.40-34.12)$ & $(23.70-35.37)$ & $(30.00-35.12)$ & $(26.15-38.47)$ & $(22.44-29.35)$ & $(20.79-28.50)$ & & \\
\hline & \multirow{2}{*}{ A } & 33.66 & 32.63 & 33.59 & 33.67 & $37.55^{*}$ & 33.33 & \multirow{2}{*}{0.002} & $P_{3}=0.038$ \\
\hline & & (30.30-35.89) & (27.20-36.59) & (29.32-38.15) & $(27.61-35.48)$ & (35.67-42.43) & $(31.63-40.90)$ & & $P_{12}=0.083$ \\
\hline
\end{tabular}

Group_T: tenofovir-DF/emtricitabine/ efavirenz and Group_A: abacavir/lamivudine/ efavirenz. All the results are expressed as median values and interquartile range (25 $\left.{ }^{\text {th }}-75^{\text {th }}\right)$. HLs: Human Leukocytes. $\mathrm{p}_{\text {time }}$ displays the difference within the group during the overall 12 -month treatment.

*: displays the significant difference of each time point with the baseline value $(\mathbf{p}<\mathbf{0 . 0 5})$.

$P_{\text {int }}$ displays the difference between the two groups during the overall 12-month treatment.

$\mathrm{P}_{\text {specific-time-point }}$ displays the significant difference between the two groups at a specific time point. 


\section{Comparison of Bound PAF levels between the ART groups}

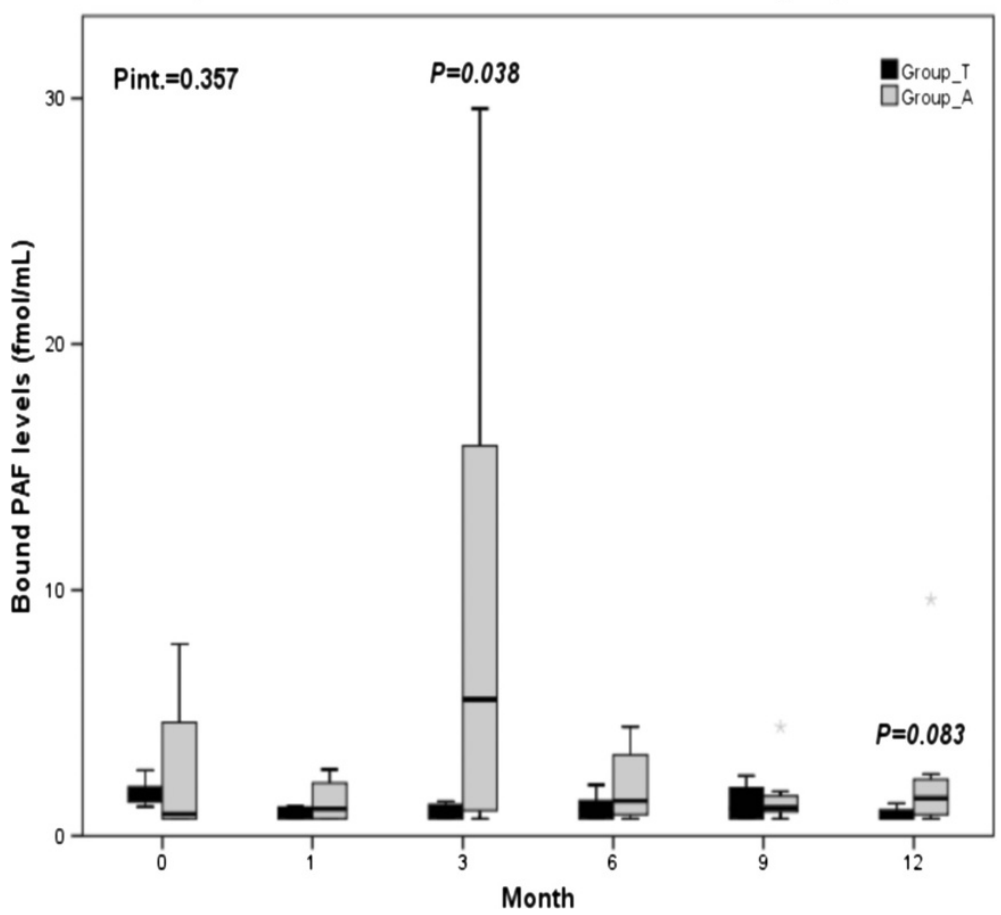

Figure 1 Comparison of Bound PAF levels between the ART groups, Group_T: tenofovir-DF/emtricitabine/efavirenz, Group_A: abacavir/lamivudine/efavirenz, Data are expressed as median values and interquartile range $\left(25^{\text {th }}-75^{\text {th }}\right)$. Pint. displays the overall difference between the two groups. P displays the difference at a particular time point of the study occurred from the comparison of the two groups.

month $\left(\mathrm{p}_{1}=0.016, \mathrm{p}_{3}=0.008, \mathrm{p}_{6}=0.047, \mathrm{p}_{9}=0.008\right.$ and $\mathrm{p}_{12}=0.008$, respectively). In contrast, in Group_A it is borderline differentiated through the study period ( $\mathrm{p}_{\text {time_A }}=0.085$ ), achieving however an increase, at the $12^{\text {th }}$ month $\left(\mathrm{p}_{12}=0.006\right)$. Although the comparison of the two groups presents no overall differentiation $\left(P_{\text {int }}=0.304\right)$, there is a significant one at the $12^{\text {th }}$ month $\left(\mathrm{p}_{12}\right.$ A-T $\left.=0.016\right)$. Regarding the specific activity of lyso-PAF-AT, in Group_T it is differentiated during the 12-month treatment $\left(\mathrm{p}_{\text {time_T }}=0.002\right)$ with significant decreases from the $6^{\text {th }}$ to the $12^{\text {th }}$ month ( $\mathrm{p}_{6}=0.008, \mathrm{p}_{9}=0.008, \mathrm{p}_{12}=0.008$, respectively). On the contrary, in Group_A, no difference is observed throughout the study period $\left(\mathrm{p}_{\text {time_A }}=0.141\right)$, however, an increase is detected at the $3^{\text {rd }}$ month $\left(p_{3}=0.037\right)$; (Table 1).

Regarding PAF biosynthesis in platelets, in Group_T the specific activity of PAF-CPT remains stable through time $\left(\mathrm{p}_{\text {time_T }}=0.343\right)$ with a reduction, however, at the $12^{\text {th }}$ month $\left(\mathrm{p}_{12}=0.047\right)$. Besides, the specific activity of lysoPAF-AT in Group_T remains stable through the 12month period $\left(\mathrm{p}_{\text {time_T }}=0.416\right)$, decreasing though at the $9^{\text {th }}$ month $\left(p_{9}=0.039\right)$, while in Group_A it is differentiated during the study period $\left(\mathrm{p}_{\text {time_A }}=0.041\right.$ ) with a significant peak at the $3^{\text {rd }}$ month of treatment $\left(\mathrm{p}_{3}=0.010\right)$; (Additional file 2).
Effect of ART regimens on both catabolic isoforms of PAF-acetylhydrolase: Lp-PLA2 in plasma and PAF-AH in blood cells

The specific activity of Lp-PLA2 in plasma presents significant variations throughout the study period in both ART groups $\left(p_{\text {time_T }}=0.003\right.$ and $\left.\mathrm{p}_{\text {time_A }}=0.002\right)$; (Figure 2$)$. Specifically, in Group_T it is decreased at the $9^{\text {th }}$ and $12^{\text {th }}$ month $\left(\mathrm{p}_{9,12}=0.008\right)$, while in Group_A, it is increased at the $9^{\text {th }}$ month $\left(\mathrm{p}_{9}=0.002\right)$, (Additional file 2 ).

Regarding the specific activity of PAF-AH in leukocytes, in Group_T it is differentiated through the 12month period $\left(\mathrm{p}_{\text {time_}} \mathrm{T}=0.002\right)$, with significant decreases from the $6^{\text {th }}$ to the $12^{\text {th }}$ month $\left(\mathrm{p}_{6}=0.031, \mathrm{p}_{9}=0.016\right.$ and $\mathrm{p}_{12}=0.008$, respectively). In contrast, in Group_A, the specific activity of PAF-AH is not differentiated during the study period, achieving however a significant peak at the $3^{\text {rd }}$ month $\left(\mathrm{p}_{3}=0.049\right)$, (Table 1$)$.

Concerning the specific activity of PAF-AH in platelets, only in Group_ $T$ it is differentiated through the 12 -month period $\left(\mathrm{p}_{\text {time_}} \mathrm{T}=0.023\right)$, with significant reductions from the $6^{\text {th }}$ to the $12^{\text {th }}$ month $\left(\mathrm{p}_{6}=0.016, \mathrm{p}_{9}=0.008\right.$ and $\mathrm{p}_{12}=0.008$, respectively), (Additional file 2 ).

In vivo effect of ART regimens on cytokines' levels Cytokines' levels remain stable through the study period in both groups ( $\left.\mathrm{p}^{\prime} \mathrm{s}_{\text {time }}>0.05\right)$, although a single increase 


\section{Comparison of Lp-PLA2 specific activity between the ART groups}

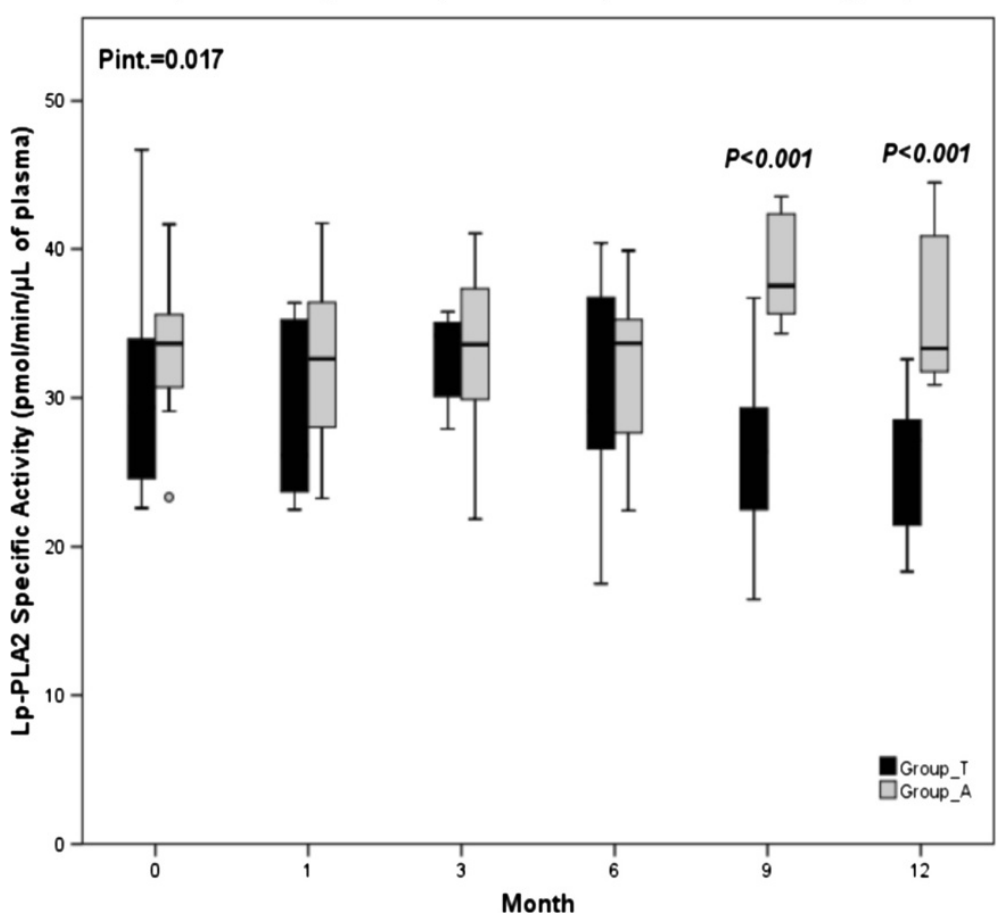

Figure 2 Comparison of Lp-PLA2 specific activity between the ART groups, Group_T: tenofovir-DF/emtricitabine/efavirenz, Group_A: abacavir/lamivudine/efavirenz, Data are expressed as median values and interquartile range $\left(25^{\text {th }}-75^{\text {th }}\right)$. Pint. displays the overall difference between the two groups. P displays the difference at a particular time point of the study occurred from the comparison of the two groups.

of TNF $\alpha$ levels in Group_A $\left(\mathrm{p}_{1}=0.027\right)$ is observed at the $1^{\text {st }}$ month of treatment, (Additional file 3 ).

\section{Discussion}

Over the last 18 years, ART succeed in raising CD4 cell counts and suppressing viral load which has remarkably improved the course of HIV-disease, with longer survival and improved quality of life [2]. At the same time, it has led to the appearance of previously unrecognized chronic complications, such as ischemic cardiovascular events, cancer and nephropathy [41]. It is not clear yet whether these manifestations are related to the ART administration or the virus itself. Even patients under antiretroviral therapy with undetectable viral load present long-term immune activation and chronic inflammation $[1,2]$. Therefore the blocking of the above mechanisms could be a parallel therapeutic approach. Although it has been suggested that persistent inflammation is implicated in chronic non-HIV related manifestations, it is not clear yet which inflammatory mediators could be used in clinical practice in order to reduce HIV morbidity and mortality.

Our team has already shown that tenofovir-DF/emtricitabine/efavirenz has great in vitro inhibitory effect against PAF [25] and decreases PAF biosynthesis during a 6-month treatment period [34] while abacavir/lamivudine/efavirenz has limited in vitro inhibitory effect [25] against PAF and increases at the $3^{\text {rd }}$ month lyso-PAFAT, which is implicated in acute inflammatory processes [35]. The present study expands the previous data by providing the effect of these ART regimens on PAF levels during a 12-month period and the follow-up of PAF metabolic enzymes' activity at the $9^{\text {th }}$ and $12^{\text {th }}$ month along with the levels of selected HIV-implicated cytokines (IL-1 $\beta$, IL-6, IL-8, IL-10, IL-12p70, TNF $\alpha$ and VEGF).

In the present study, PAF levels in HIV patients are measured for the first time, resulting surprisingly to lower values than the average population although the activity of PAF biosynthetic enzymes is much higher [42]. One may suggest that a possible explanation may be the increased activity of PAF catabolic enzyme, namely PAF-AH for the cellular isoform and Lp-PLA2 for the plasma isoform, acting in order to counterbalance PAF levels in blood. In addition, another possible explanation for PAF decreased levels is the lower white blood cell counts in HIV patients compared to healthy population. The comparison of PAF levels between the two groups reveals a significant increase in Group_A at the $3^{\text {rd }}$ month. This differentiation is probably attributed 
to the peak of lyso-PAF-AT activity at the $3^{\text {rd }}$ month in Group_A in parallel with the continual decrease of PAF biosynthesis in Group_T. There is also a trend of difference at PAF levels noted at the $12^{\text {th }}$ month, which may be credited to the significant difference at the $12^{\text {th }}$ month of PAF-CPT as well to the opposite effect of the two regimens on both biosynthetic enzymes. The above results of higher PAF levels and metabolic enzymes' activity, seen at certain time points, support a possible direct effect of abacavir than an indirect effect of immune reconstitution as it occurs from the white blood cell count.

In this study the activity of Lp-PLA2, a well-known cardiovascular risk marker and sensitive to PAF levels [43], is higher than the average population [42]. Increased PAF levels seem to increase Lp-PLA2 activity in order to adjust PAF levels in blood and this may be the reason of the significant overall differentiation of Lp-PLA2 activity between the two groups spotted particularly at the $9^{\text {th }}$ and the $12^{\text {th }}$ month. Moreover, in Group_T the decrease of LpPLA2 at the $9^{\text {th }}$ and the $12^{\text {th }}$ month comes in accordance with the decrease in PAF levels during the 12-month period. In Group_A the increase of PAF levels at the $3^{\text {rd }}$ month may be the reason of Lp-PLA2 raise at the $9^{\text {th }}$ month or this raise possibly reflects a direct effect of abacavir/lamivudine/efavirenz on this enzyme.

The inflammatory cytokines IL-1 $\beta$, IL-6, IL-10, IL12p70 and TNF $\alpha$ are implicated both at the pathogenesis and the morbidities of HIV infection. In the present study, cytokines' levels are higher than healthy population indicating the immune state of these HIV patients [44]. Cytokines' levels remain stable between and within ART groups during the study period apart from an increase of TNFo levels at the $1^{\text {st }}$ month in Group_A. The elevated TNF $\alpha$ levels may assist to the increased PAF levels at the $3^{\text {rd }}$ month, knowing that TNF $\alpha$ induces PAF biosynthesis and vice versa $[45,46]$.

\section{Conclusion}

In conclusion the present study points out the effect of ART regimens to the persistent inflammatory state observed in the setting of suppressive antiretroviral treatment. The tested regimens caused an opposite outcome on PAF levels and on Lp-PLA2 activity. Since PAF is a potent inflammatory factor, associated with pro-atherosclerotic complications, the above results indicate a potent antiinflammatory role for tenofovir based regimen while suggest PAF as the missing link between the abacavir based regiment and the reported cardiovascular risk.

\section{Study limitations}

The main limitation of this research study is the number of the samples. The reason is the chosen methods for PAF which are quite strenuous and time consuming but also more sensitive and trustful than other rapid methods.
Female patients have not been used in the study as the menstrual cycle affects the metabolism of PAF.

\section{Additional files}

Additional file 1: Anthropometric and biochemical characteristics of ART groups.

Additional file 2: Free PAF levels and metabolic enzymes in platelets of ART groups.

Additional file 3: Cytokines and VEGF levels in HIV-infected patients.

\section{Competing interests}

The authors declare no competing Interests. The research has been funded from the Hellenic Society for the Research, Study and Education in Infectious Diseases.

\section{Authors' contributions}

V.D.P is responsible for the authorship, the experiments and the data analysis. G.S and A.B.T participated at the experiments and the data analysis. M.C, N.M and N.T designed the selection of patient samples, provided the clinical data for analysis and contributed to the interpretation of data, revising drafts critically for important intellectual content and final approval of the version to be published. E.F conducted the data analysis and reviewed the manuscript. S.A critically reviewed the manuscript. C.A.D and M.C.L conceived and supervised the whole study. All authors read and approved the final manuscript.

\section{Acknowledgments}

The authors would like to thank Chryssa Papasteriades, MD of the Department of Immunology and Histocompatibility in Evangelismos Hospital, for providing us the flow cytometer for the cytokines' data analysis and Demosthenis Panagiotakos, professor in the Department of Science Nutrition-Dietetics in Harokopio University, for his advice concerning the statistical analysis. The study was funded from the Hellenic Society for the research study and education on infectious diseases.

\section{Author details}

${ }^{1}$ Faculty of Chemistry, National \& Kapodistrian University of Athens, Panepistimioupolis Zografou, 15771 Athens, Greece. ${ }^{2} 3$ rd Internal Medicine Department-Infectious Diseases Unit, Red Cross General Hospital, Athens, Greece. ${ }^{3}$ Department of Immunology and Histocompatibility, Evangelismos Hospital, Athens, Greece. ${ }^{4}$ Department of Science Nutrition-Dietetics, Harokopio University, Athens, Greece. ${ }^{5} 1$ st Internal Medicine Department-Infectious Diseases Unit, "G. Gennimatas" Hospital, Athens, Greece.

Received: 5 April 2014 Accepted: 24 May 2014

Published: 29 May 2014

\section{References}

1. Taiwo B, Barcena L, Tressler R: Understanding and controlling chronic immune activation in the HIV-infected patients suppressed on combination antiretroviral therapy. Curr HIV/AIDS Rep 2013, 10:21-32.

2. Hunt PW: HIV and inflammation: mechanisms and consequences. Curr HIV/AIDS Rep 2012, 9:139-147.

3. Plaeger SF, Collins BS, Musib R, Deeks SG, Read S, Embry A: Immune activation in the pathogenesis of treated chronic HIV disease: a workshop summary. AIDS Res Hum Retroviruses 2012, 28:469-477.

4. Miller CJ, Baker JV, Bormann AM, Erlandson KM, Huppler Hullsiek K, Justice AC, Neuhaus J, Paredes R, Petoumenos K, Wentworth D, Winston A, Wolfson J, Neaton JD, Insight S, Groups ES: Adjudicated Morbidity and Mortality Outcomes by Age among Individuals with HIV Infection on Suppressive Antiretroviral Therapy. PloS one 2014, 9:e95061.

5. Venketaraman V, Morris D, Donohou C, Sipin A, Kung S, Oh H, Franklin M, Murad JP, Khasawneh FT, Saviola B, Guilford T, Donahue C: Role of Cytokines and Chemokines in HIV Infection. In HIV and AIDS - Updates on Biology, Immunology, Epidemiology and Treatment Strategies. Edited by Dumais N. Croatia: InTech; 2011:281-300. 
6. MacLeod IJ, Rowley CF, Lockman S, Ogwu A, Moyo S, van Widenfelt E, Mmalane M, Makhema J, Essex M, Shapiro RL: Abacavir alters the transcription of inflammatory cytokines in virologically suppressed, HIV-infected women. J Int AIDS Soc 2012, 15:17393.

7. Lundgren J, Neuhaus J, Babiker A, Cooper D, Duprez D, El-Sadr W, Emery S, Gordin FM, Kowalska J, Phillips A, Prineas R, Reiss P, Sabin CA, Tracy R, Weber R, Grund B, Neaton J: Use of nucleoside reverse transcriptase inhibitors and risk of myocardial infarction in HIV-infected patients. AIDS 2008, 22:F17-F24.

8. Palella FJ Jr, Gange SJ, Benning L, Jacobson L, Kaplan RC, Landay AL, Tracy $\mathrm{RP}$, Elion R: Inflammatory biomarkers and abacavir use in the Women's Interagency HIV Study and the Multicenter AIDS Cohort Study. AIDS 2010, 24:1657-1665.

9. Padilla S, Masia M, Garcia N, Jarrin I, Tormo C, Gutierrez F: Early changes in inflammatory and pro-thrombotic biomarkers in patients initiating antiretroviral therapy with abacavir or tenofovir. BMC Infect Dis 2011, $11: 40$.

10. Kim C, Gupta SK, Green L, Taylor BM, Deuter-Reinhard M, Desta Z, Clauss M: Abacavir, didanosine and tenofovir do not induce inflammatory, apoptotic or oxidative stress genes in coronary endothelial cells. Antivir Ther 2011, 16:1335-1339.

11. Demopoulos CA, Pinckard RN, Hanahan DJ: Platelet-activating factor. Evidence for 1-0-alkyl-2-acetyl-sn-glyceryl-3-phosphorylcholine as the active component (a new class of lipid chemical mediators). J Biol Chem 1979, 254:9355-9358.

12. Zimmerman GA, Mclntyre TM, Prescott SM, Stafforini DM: The platelet-activating factor signaling system and its regulators in syndromes of inflammation and thrombosis. Crit Care Med 2002, 30:S294-S301.

13. Stafforini DM, McIntyre TM, Zimmerman GA, Prescott SM: Platelet-activating factor, a pleiotrophic mediator of physiological and pathological processes. Crit Rev Clin Lab Sci 2003, 40:643-672.

14. Demopoulos CA, Karantonis HC, Antonopoulou S: Platelet activating factor - a molecular link between atherosclerosis theories. Eur J Lipid Sci Technol 2003, 105:705-716.

15. Snyder F: Platelet-activating factor and its analogs: metabolic pathways and related intracellular processes [published errata appear in Biochim Biophys Acta 1995 Aug 3;1257(3):297 and 1995 Oct 26;1259(1):121]. Acta Biochim Biophys 1995, 1254:231-249.

16. Snyder F: CDP-choline:alkylacetylglycerol cholinephosphotransferase catalyzes the final step in the de novo synthesis of platelet-activating factor. Bba-Lipid Lipid Met 1997, 1348:111-116.

17. Shindou H, Hishikawa D, Nakanishi H, Harayama T, Ishii S, Taguchi R, Shimizu T: A single enzyme catalyzes both platelet-activating factor production and membrane biogenesis of inflammatory cells. Cloning and characterization of acetyl-CoA:LYSO-PAF acetyltransferase. J Biol Chem 2007, 282:6532-6539.

18. Stafforini DM, Prescott SM, Mclntyre TM: Human plasma platelet-activating factor acetylhydrolase. Purification and properties. J Biol Chem 1987, 262:4223-4230.

19. Genis P, Jett M, Bernton EW, Boyle T, Gelbard HA, Dzenko K, Keane RW, Resnick L, Mizrachi Y, Volsky DJ, Epstein LG, Gendelman HE: Cytokines and arachidonic metabolites produced during human immunodeficiency virus (HIV)-infected macrophage-astroglia interactions: implications for the neuropathogenesis of HIV disease. J Exp Med 1992, 176:1703-1718.

20. Del Sorbo L, Arese M, Giraudo E, Tizzani M, Biancone L, Bussolino F, Camussi G: Tat-induced platelet-activating factor synthesis contributes to the angiogenic effect of HIV-1 Tat. Eur J Immunol 2001, 31:376-383.

21. Biancone L, Cantaluppi V, Boccellino M, Bussolati B, Del Sorbo L, Conaldi PG, Albini A, Toniolo A, Camussi G: Motility induced by human immunodeficiency virus-1 Tat on Kaposi's sarcoma cells requires platelet-activating factor synthesis. Am J Pathol 1999, 155:1731-1739.

22. Perry SW, Hamilton JA, Tjoelker LW, Dbaibo G, Dzenko KA, Epstein LG, Hannun Y, Whittaker JS, Dewhurst S, Gelbard HA: Platelet-activating factor receptor activation. An initiator step in HIV-1 neuropathogenesis. J Biol Chem 1998, 273:17660-17664.

23. Arese M, Ferrandi C, Primo L, Camussi G, Bussolino F: HIV-1 Tat protein stimulates in vivo vascular permeability and lymphomononuclear cell recruitment. J Immunol 2001, 166:1380-1388.

24. Doublier S, Zennaro C, Spatola T, Lupia E, Bottelli A, Deregibus MC Carraro M, Conaldi PG, Camussi G: HIV-1 Tat reduces nephrin in human podocytes: a potential mechanism for enhanced glomerular permeability in HIV-associated nephropathy. AIDS 2007, 21:423-432.

25. Tsoupras AB, Chini M, Tsogas N, Fragopoulou E, Nomikos T, Lioni A, Mangafas N, Demopoulos CA, Antonopoulou S, Lazanas MC: Anti-plateletactivating factor effects of highly active antiretroviral therapy (HAART): a new insight in the drug therapy of HIV infection? Aids Res Human Retroviruses 2008, 24:1079-1086

26. Martin M, Serradji N, Dereuddre-Bosquet N, Le Pavec G, Fichet G, Lamouri A Heymans F, Godfroid JJ, Clayette P, Dormont D: PMS-601, a new plateletactivating factor receptor antagonist that inhibits human immunodeficiency virus replication and potentiates zidovudine activity in macrophages. Antimicrob Agents Chemother 2000, 44:3150-3154.

27. Sallem W, Serradji N, Dereuddre-Bosquet N, Dive G, Clayette P, Heymans F: Structure-activity relationships in platelet-activating factor. Part 14: synthesis and biological evaluation of piperazine derivatives with dual anti-PAF and anti-HIV-1 activity. Bioorg Med Chem 2006, 14:7999-8013.

28. Serradji N, Bensaid O, Martin M, Sallem W, Dereuddre-Bosquet N, Benmehdi H, Redeuilh C, Lamouri A, Dive G, Clayette P, Heymans F: Structure-activity relationships in platelet-activating factor. Part 13: synthesis and biological evaluation of piperazine derivatives with dual anti-PAF and anti-HIV-1 or pure antiretroviral activity. Bioorg Med Chem 2006, 14:8109-8125.

29. Tsoupras AB, Chini M, Mangafas N, Tsogas N, Stamatakis G, Tsantila N, Fragopoulou E, Antonopoulou S, Gargalianos P, Demopoulos CA, Lazanas MC: Platelet-activating factor and its basic metabolic enzymes in blood of naive HIV-infected patients. Angiology 2012, 63:343-352.

30. Khovidhunkit W, Memon RA, Shigenaga JK, Pang M, Schambelan M, Mulligan K Feingold KR, Grunfeld C: Plasma platelet-activating factor acetylhydrolase activity in human immunodeficiency virus infection and the acquired immunodeficiency syndrome. Metabolism 1999, 48:1524-1531.

31. Eggert D, Dash PK, Serradji N, Dong CZ, Clayette P, Heymans F, Dou H, Gorantla S, Gelbard HA, Poluektova L, Gendelman HE: Development of a platelet-activating factor antagonist for HIV-1 associated neurocognitive disorders. J Neuroimmunol 2009, 213:47-59.

32. Persidsky Y, Limoges J, Rasmussen J, Zheng J, Gearing A, Gendelman HE: Reduction in glial immunity and neuropathology by a PAF antagonist and an MMP and TNFalpha inhibitor in SCID mice with HIV-1 encephalitis. J Neuroimmunol 2001, 114:57-68.

33. Schifitto G, Sacktor N, Marder K, McDermott MP, McArthur JC, Kieburtz K, Small S, Epstein LG: Randomized trial of the platelet-activating factor antagonist lexipafant in HIV-associated cognitive impairment. Neurological AIDS Research Consortium. Neurology 1999, 53:391-396.

34. Chini M, Tsoupras AB, Mangafas N, Tsogas N, Papakonstantinou VD, Fragopoulou E, Antonopoulou S, Gargalianos P, Demopoulos CA, Lazanas MC: Effects of HAART on platelet-activating factor metabolism in naive HIV-infected patients I: study of the tenofovir-DF/emtricitabine/efavirenz HAART regimen. AIDS Res Hum Retroviruses 2012, 28:766-775.

35. Chini M, Tsoupras AB, Mangafas N, Tsogas N, Papakonstantinou VD, Fragopoulou E, Antonopoulou S, Gargalianos P, Demopoulos CA, Lazanas MC: Effects of highly active antiretroviral therapy on platelet activating factor metabolism in naive HIV-infected patients: ii) study of the abacavir/ lamivudine/efavirenz HAART regimen. Int J Immunopathol Pharmacol 2012, 25:247-258.

36. Clumeck N, Pozniak A, Raffi F, Committee EE: European AIDS Clinical Society (EACS) guidelines for the clinical management and treatment of HIV-infected adults. HIV medicine 2008, 9:65-71.

37. Services DoHaH: Panel on Antiretroviral Guidelines for Adults and Adolescents. Guidelines for the use of antiretroviral agents in HIV-1-infected adults and adolescents. ; 2009:1-161.

38. Demopoulos CA, Andrikopoulos NK, Antonopoulou S: A simple and precise method for the routine determination of platelet-activating factor in blood and urine. Lipids 1994, 29:305-309.

39. Bligh EG, Dyer WJ: A rapid method of total lipid extraction and purification. Can J Biochem Physiol 1959, 37:911-917.

40. Kolovou V, Papakonstantinou VD, Stamatakis G, Verouti SN, Xanthopoulou MN, Kolovou G, Demopoulos CA: Platelet activating factor levels and metabolism in tangier disease: a case study. Lipids Health Dis 2012, 11:89.

41. Phillips AN, Neaton J, Lundgren JD: The role of HIV in serious diseases other than AIDS. AIDS 2008, 22:2409-2418.

42. Detopoulou P, Nomikos T, Fragopoulou E, Stamatakis G, Panagiotakos DB, Antonopoulou S: PAF and its metabolic enzymes in healthy volunteers: 
interrelations and correlations with basic characteristics. Prostaglandins Other Lipid Mediat 2012, 97:43-49.

43. Packard CJ: Lipoprotein-associated phospholipase A2 as a biomarker of coronary heart disease and a therapeutic target. Curr Opin Cardiol 2009, 24:358-363.

44. Nowlan ML, Drewe E, Bulsara H, Esposito N, Robins RA, Tighe PJ, Powell RJ, Todd I: Systemic cytokine levels and the effects of etanercept in TNF receptor-associated periodic syndrome (TRAPS) involving a C33Y mutation in TNFRSF1A. Rheumatology 2006, 45:31-37.

45. Bussolino F, Camussi G, Baglioni C: Synthesis and release of plateletactivating factor by human vascular endothelial cells treated with tumor necrosis factor or interleukin 1 alpha. J Biol Chem 1988, 263:11856-11861.

46. Ruis NM, Rose JK, Valone FH: Tumor necrosis factor release by human monocytes stimulated with platelet-activating factor. Lipids 1991, 26:1060-1064

doi:10.1186/1476-511X-13-90

Cite this article as: Papakonstantinou et al: In vivo effect of two first-line ART regimens on inflammatory mediators in male HIV patients. Lipids in Health and Disease 2014 13:90.

\section{Submit your next manuscript to BioMed Central and take full advantage of:}

- Convenient online submission

- Thorough peer review

- No space constraints or color figure charges

- Immediate publication on acceptance

- Inclusion in PubMed, CAS, Scopus and Google Scholar

- Research which is freely available for redistribution 